\title{
Vínculos no ciberespaço: websites pró-anorexia e bulimia*
}

\section{RESUMO}

Análise de alguns modos de expressão dos acontecimentos comunicacionais disponibilizados pelas redes sociais da internet. Mediante a aplicação de conceitos psicanalíticos, espera-se destacar bases mais claras para a compreensão dos vínculos em geral e dos desdobramentos exemplares que tomam em websites pró anorexia-bulimia.

\section{PALAVRAS-CHAVE}

teorias da comunicação

pro-anorexia

psicanálise

\section{ABSTRACT \\ Analysis of some ways of expression of the communicational events available in the social nets of the internet. Using psycho- analytical concepts, this paper intends to provide a clearer basis to a general comprehension of the human bonds and their exemplary unfolding in web sites pro anorexia and pro buli- mia.}

\section{KEY WORDS}

communication theories

pro-anorexia

psychoanalysis

\section{Potiguara Mendes da Silveira Jr.}

Professor do Programa de Pós-Graduação em Comunicação da UFJF/MG/BR potiguaramsir@uol.com.br

\section{Vanessa Alkmin Reis}

Mestre em Comunicação e Sociedade pela UFJF/MG/BR

vanessareis84@yahoo.com.br
No final do século 19, a aparência de estar sem (do grego: ann) desejo ou apetite (orexis) serviu para nomear o que ocorria nos quadros de emagrecimento auto-induzidos, sobretudo de mulheres (dez a trinta anos) ${ }^{1}$. Chamou-se, então, de anorexia. A partir de 1970, observa-se que ela tem outro aspecto notável: está freqüentemente associada à bulimia, um quadro caracterizado por hiperfagia contumaz seguida da tentativa de neutralizar seus efeitos mediante vômitos, purgantes, laxantes, etc ${ }^{2}$ (Busse, 2004, pp. 33-34).

Atualmente, ambas são médica e psiquiatricamente classificadas como desordens ou transtornos mentais. A anorexia inclui itens como: "medo intenso da obesida$\mathrm{de}^{\prime \prime}$, "perda de $25 \%$ ou mais do peso esperado", "distúrbio da imagem corporal", e "ausência de doenças físicas" (Busse, 2004, p. 40). A bulimia compartilha vários desses itens, mas se distingue pelo consumo de grandes quantidades de comida em curto período de tempo (Busse, 2004, p. 44).

Esta é, em linhas gerais, a classificação tomada como referência por teóricos, jornalistas e articulistas, que tendem a associar a atual manifestação da anorexia/bulimia a um imperativo de beleza física inerente a nosso mundo capitalista, competitivo e global. São muitos livros, notícias e reportagens sobre: a magreza das modelos de moda, a morte de algumas delas, a proibição legal de desfilarem aquém de certo peso, a tristeza dos pais, a impotência em lidar com o fato, a responsabilidade social envolvida em seu tratamento[...]

Interessa-nos considerar a anorexia e a bulimia como fenômenos vinculares difundidos pelas redes sociais da internet $^{3}$ : suas manifestações, efeitos e direções. Isto com o objetivo de trazer contribuições ao entendimento dos modos de construção dos vínculos que se disponibilizaram amplamente a partir da década de 1990 e que não eram claramente visíveis antes por lhes faltar dispositivos técnicos de difusão adequados.

A hipótese inicial é: vários aspectos dessa nova rede sociotecnológica serão melhor apreendidos se aplicarmos à nossa metodologia alguns conceitos psicanalíticos que vêm sendo aperfeiçoados nos últimos anos. Assim procedendo, espera-se destacar bases mais adequadas para a compreensão dos vínculos em geral e dos desdobramentos exemplares que tomam em websites sobre anorexia-bulimia. De início, vejamos uma descrição do campo da pesquisa.

\section{Pró-ana/mia: comunidades}

Protegidas pelo anonimato da rede, as seguidoras da Ana e da Mia (apelidos carinhosos dados, respectivamente, à anorexia e à bulimia) encontraram em blogs, 
fóruns e sites de relacionamento lugares para falar sobre uma parte de suas vidas que, em geral, não pode ser abertamente expressa: a especificidade de sua relação com a alimentação e a imagem corporal.

Em 2000, surge um movimento pró-anorexia e próbulimia na internet. Inicialmente difundido nos Estados Unidos e Inglaterra, não demora a chegar a outros países. No Brasil, os blogs pró-ana/mia apareceram em 2002. Dois anos mais tarde, com a criação e popularização do site de relacionamentos Orkut, criam-se comunidades virtuais para reunir tanto as anas e mias que estão em tratamento, quanto as que querem permanecer nestas condições.

\section{Thinspirations}

O movimento chega a sites de compartilhamento de vídeos, como o Youtube, no qual uma busca simples pelas tags "pro ana mia" apresenta cerca de 600 resultados. Misturam-se reportagens de TV referentes ao tema, vídeos caseiros com opiniões individuais e tentativas de conscientização e alerta para seus perigos. A maioria se encaixa no que chamam de thinspirations: inspirações magras. São montagens feitas a partir de fotos e vídeos, geralmente combinados com uma música de fundo, retratando mulheres extremamente delgadas. Grande parte das imagens é de modelos e atrizes famosas. Há também thinspirations baseadas em fotos de pessoas reais, que parecem funcionar como prova de que, mediante esses comportamentos alimentares, garotas comuns podem chegar cada vez mais perto do que consideram perfeição.

Supomos ser possível identificar um perfil padrão. A maioria dos sites é composta de mulheres, o que reflete a própria estatística sobre os pacientes em tratamento por transtornos alimentares: apenas $10 \%$ são do sexo masculino. Esta maior incidência é, além de fatores sociológicos e psicológicos, atribuída a fatores hormonais e bioquímicos, como a propensão feminina a distúrbios do metabolismo da serotonina.

São, sobretudo, jovens entre 13 e 17 anos. Como, essencialmente, as usuárias se apresentam com perfil falso para não serem facilmente identificadas, tomamos como base a idade que informam. Indícios de adolescência podem ser detectados na escrita tipicamente "internética", com diminutivos, abreviações, letras repetidas, etc. Com frequência, aparecem nos perfis fotografias de ídolos teen, particularmente os que já tiveram algum histórico de ana e mia, como a cantora Anahí, do grupo RBD, e a atriz Nicole Richie.

Muitas afirmam que a sociedade lhes impõe que sejam magras, que vêem dia após dia que só as magras conseguem popularidade, respeito, sucesso amoroso e aceitação. Como exemplo, estampam imagens de atrizes e modelos donas de corpos - e, consequentemente, de modos de vida - perfeitos. Embora possam variar, dependendo da nacionalidade da blogueira, Angelina Jolie e Victoria Beckham são praticamente unanimidades. Os homens também têm seus "musos": famosos magros como Daniel de Oliveira (especialmente na interpretação de Cazuza, no filme homônimo) e Daniel Radcliffe, intérprete do bruxo Harry Potter no cinema. Popular também é a tatuagem de Angelina Jolie com os dizeres latinos quod me nutrit, me destruit - em português, o que me alimenta me destrói. Várias garotas relatam o desejo de se tatuar a mesma frase, algumas realmente o fizeram.

Juntamente com as fotografias, os lemas compõem parte importante das inspirações de magreza postadas na rede. Frases como "se é saboroso, está tentando te matar", "um minuto na sua boca, a vida toda no seu quadril" e "um corpo imperfeito reflete uma pessoa imperfeita" mostram a insatisfação com seus corpos e a busca incessante pelo que podem se tornar seguindo tais indicações. Estas frases viram títulos de blogs, posts, comunidades, e são mescladas a fotografias de pessoas magras em vídeos motivacionais compartilhados online.

\section{Sociedade secreta: rede de apoio mútuo}

O mundo virtual pró-ana e mia assume um caráter de sociedade secreta, com algumas práticas seguidas com afinco quase religioso. Nas comunidades do Orkut, por exemplo, são comuns as temporadas de no food (NF) e low food (LF) coletivos, em que as garotas organizam uma rede de apoio mútuo durante o tempo de restrição alimentar. Como o processo ocorre às escondidas da família e amigos, a dicas para camuflar essas práticas é um dos tópicos mais acessados. Sugestões como levar o aparelho de som para o banheiro ou ligar o chuveiro para abafar o som dos vômitos geram um clima de compreensão, conforto e aceitação que geralmente não é sentido no convívio social.

Alguns textos são repassados na internet como "literatura" do movimento. Um dos mais difundidos é a carta de uma suposta anoréxica hospitalizada, que ilustra o desejo da magreza última ${ }^{4}$. Muito populares também são a Carta da $A n a^{5}$ e a Carta da $M i a^{6}$, repetidas em quase todas as comunidades observadas. Funcionam como uma espécie de "carta de apresentação", mostrando, principalmente às iniciantes, os benefída anorexia e da bulimia, mostrando os benefças, masam de ouvir: frases como "cios da prática NF/LF. Até um objeto de identificação foi criado para que se reconheçam. Para as anas, pulseiras vermelhas, para as mias, roxas.

\section{Padrão: magreza extrema (e morte)}

O padrão de magreza extrema é considerado o ideal, embora reconheçam que desagrada a muitos. As opiniões de familiares, amigos e parceiros amorosos de que já estariam magras demais são consideradas meras tentativas de demovê-las de seus objetivos. Frases como "não importa o que falem, vou atingir minha meta", "nunca se está magra demais" etc., e incentivos para deixar "os ossinhos aparecerem" são comuns e funcionam como combustível para uma luta incessante contra a comida.

O desejo de pesar por volta de 35 quilos e a insatisfa- 
ção em não conseguir são marcas constantes em seus perfis. Por mais baixo que seja uma vez atingido o peso, nova meta é estabelecida e a busca continua. Sintomas como fraqueza, tontura e desmaios são valorizados como indícios de vitória. A comunidade Estar fraca é ser forte, por exemplo, reúne 260 membros com a seguinte descrição: "Depois de dias de LF, ou (principalmente) NF, bate aquela tontura, você perde o equilíbrio, a vista escurece, dá uma fraqueza... Só mostra o quanto você foi forte por ter agüentado até ali!"

A morte, que acomete cerca de $10 \%$ dos diagnosticados, em geral é considerada uma conseqüência indesejada, mas não um empecilho. Pessoas como a modelo Ana Carolina Reston, falecida em 2006 com peso corporal de 40 quilos, são reverenciadas como "mártires da causa". Os tópicos de discussão demonstram que a maioria delas tem consciência de que o mesmo pode lhes acontecer, mas a declaração mais freqüente é a da disposição para "morrer lutando".

\section{0 movimento fundamental}

Se é para "morrer lutando", temos aí, no mínimo, um ponto discordante da impressão dos médicos de que as anoréxicas estão "sem desejo". Assim sendo, para além da referência negativa ao apetite, abordar afirmativamente esta disposição de luta pode se mostrar produtivo para nossa análise.

Tomaremos, então, o conceito de pulsão de morte (Todestrieb), que exprime um movimento que Freud (1920) descobre estar necessariamente presente no psiquismo. Ele o qualifica como "de morte" por constatar que, inevitavelmente, se dirige à sua própria extinção enquanto movimento, e o opõe a uma pulsão de vida. Hoje, mais avançados nos estudos do conceito e seus desdobramentos, podemos reforçar algo que Freud indica, mas não desenvolve ${ }^{7}$. A saber, que esta segunda pulsão, na verdade, é apenas efeito da pulsão de morte, pois a vida pode ser considerada mera resistência ao movimento de extinção expresso no conceito único de Pulsão, agora não apenas circunscrito ao psiquismo, mas fundamentalmente estendido a tudo que há.

Esta ampliação do alcance do conceito reafirma que a direção pulsional se refere a uma experiência traumáti$\mathrm{ca}^{8}$, inarredável e irredutível para tudo (homem e cosmo), e destaca que, essencialmente, só há mesmo movimento para a extinção, para não mais haver, e não para haver (Magno, 1986, pp. 61-75). Supomos que sua aplicação possa dar um sentido mais claro às intencionalidades adscritas aos vínculos, sobretudo por retirar a metodologia de análise da nodulação conceitual do ser, da verdade e do sujeito, que tem norteado a maioria das abordagens dos estudos da comunicação. São abordagens devedoras de práticas interpretativas de linhagem filosófica ${ }^{9}$, as quais, por mais refinadas que sejam, não têm como se dirigir a acontecimentos como o das anas e mias sem o contraponto, implícito ou explícito, de uma vontade vitalista tida como fundamental, verdadeira, saudável e, no fim, objetivável como normal.

A tentativa é considerar os fatos não interpretativamente, já que a atual transfusão informacional e a onipresente comunicação mediada por computadores têm evidenciado que, no fim das contas, qualquer interpretação não passa de ser mais uma entre outras, e só pode ser tomada como referência para a análise em função de conjunções interesseiras das forças da situação estabelecida. Alguns autores querem ver nesta transfusão um niilismo ou a expressão de um difuso e cínico ambiente pós-moderno planetariamente instalado. De nossa parte, parece mais preciso avançar na suposição de que os acontecimentos contemporâneos já explicitaram bastante o vigor generalizado de um relativismo que a todo o momento, para bem ou para mal, denuncia conteúdos ideológicos e coloca em questão qualquer referência hermenêutica que se queira hegemônica.

De partida, então, colocamos algumas perguntas para estudo: o que anas e mias buscariam expressar ao se conectarem em rede? Sua expressão visaria "interagir com outros usuários" e "construir identidade social"10? Criar "espaços de organização social" e de "constituição do self'11? Nossa tentativa de respostas - pois, certamente, não há a resposta - toma o aspecto pulsional como referência para acompanhar este modo de produção e difusão vincular - comunicacional, portanto cada vez mais presente nas redes sociais da internet. Considerando-a uma produção que diz respeito ao humano $^{12}$ como experiência própria e legítima, cabe-nos entender seus níveis e as consequiências de seu enredamento sociotecnológico. Continuemos a descrição do campo da pesquisa.

\section{Especialização e dispersão da ana e mia}

As primeiras comunidades virtuais, bem como os primeiros blogs e fóruns eram, em sua maioria, descritos apenas como pró-ana e pró-mia. A comunidade Ana e Mia por região, por exemplo, cujo objetivo é aproximar pessoas por critérios geográficos, tem hoje 1.662 membros $^{13}$. Já a NF e LF, destinada à organização e ao suporte de temporadas de jejum coletivo total ou parcial, é uma das que têm vida mais longa, com início em 31 de janeiro de 2006 e quase 2.500 participantes. Além disso, vários subgrupos têm sido criados para dar conta de aspectos mais específicos do assunto e/ou das diversas interseções com outros temas.

A comunidade Meninos anoréxicos, com 138 membros, surgiu para discutir as especificidades do sexo masculino. No grupo Anas/mias e fumantes, com 196 participantes, há discussões sobre os efeitos do cigarro. No grupo Annas Veggies, 61 pessoas falam sobre receitas vegetarianas de baixas calorias. No Vídeos pró ana/mia, 324 participantes trocam dicas de vídeos motivacionais.

Em Músicas Anna/mia, 219 membros conversam sobre músicas que tratam do tema. Diversas bandas, sobretudo de língua inglesa, vêm compondo, gravando e vendendo músicas, embora a maioria não se defina como 
pró-ana. Em seu blog ${ }^{14}$, a cantora norte-americana Jill Sobule manifesta surpresa ao digitar seu nome em uma ferramenta de busca na Internet e obter entre os resultados diversos sites ana e mia. $O$ fato se deve a duas de suas músicas, Supermodel e Lucy at the Gym, citadas como "thinspiration" nessas páginas. A primeira, da trilha sonora do filme As patricinhas de Beverly Hills (Clueless, 1995), expressa o desejo de se tornar modelo e ser invejada em versos como "eu sou jovem e sou legal e sou bonita/eu serei uma supermodelo / eu não comi ontem / eu não vou comer hoje/eu não vou comer amanhã/eu serei uma supermodelo". A segunda, conta a história de Lucy, garota que não come e não sai da academia de ginástica, mesmo com os ossos despontando por baixo das roupas esportivas. Na última estrofe, ela não aparece mais na academia, o que leva a crer que teria morrido e ido para um céu "onde todos são bonitos e magros".

Em um fórum sobre letras de músicas ${ }^{15}$, usuários discutem sobre a faixa Me and Mia, da banda norte-americana Ted Leo and the Pharmacists. Com o refrão "você acredita em algo belo?/ Então se levante e seja isso", a canção trata de diversos pontos comuns à rotina ana e mia: busca do autocontrole, insatisfação com a própria imagem e aspecto franzino do corpo submetido a dietas restritivas. Como podemos ver em outras comunidades do tipo, há algo quase místico na luta para atingir o ideal. Na música citada, temos versos como "nós continuamos, como se estivéssemos numa missão/os últimos de uma grande tradição [...] doente pela minha dependência/combatendo a comida para alcançar a transcendência". Mostra-se também certa obstinação em sumir: "Será que ninguém aqui vai te deixar desaparecer?/nem os médicos, nem sua mãe e seu pai/mas só eu, a Mia e a Ana/sabemos o quão duro você tenta".

Observa-se nesta crescente especialização e conseqüente dispersão o reflexo das tendências da cultura contemporânea: a customização de produtos, serviços e experiências, projetada para atender a demandas cada vez mais individualizadas; e a hiperconexão dos temas disponibilizados na rede, pois, uma vez postados, formam nós aptos a conectar quaisquer outros, a permanecer enquanto durar o interesse dos envolvidos, e a permanentemente criar novas conexões.

\section{A impossível saída}

Para finalizar a exposição dos conceitos que orientam nossa análise, temos que o movimento pulsional não se exprime claramente - daí uma das declaradas dificuldades de Freud em demonstrá-lo -, mas sua vigência pode ser inferida da resistência a ele. Resistência esta, aliás, que caracteriza tudo que há e tudo que se arrola como vida, como biós (filosófico ou biológico).

Entenderemos melhor se acrescentarmos que este movimento, a cada vez que atinge o ponto máximo de aproximação de sua extinção, que é seu objetivo último, depara-se com a impossibilidade de realizá-lo em presença, pois se o fizesse extinguir-se-ia enquanto movimento.
Então, em função desta impossibilidade definitiva de sumir, só lhe resta recompor-se e "retornar" (entre aspas, pois não saiu, não há um "fora") ao que há. Colocase, assim, para o caso do humano, uma verdadeira condenação: existir numa imanência que não cessa de requerer uma transcendência que se revela sem transcendente, puro vazio. A permanente referência a esta situação sem saída pode ser detectada no decorrer da história em depoimentos de poetas ${ }^{16}$ e místicos ${ }^{17}$, em invenções científicas e artísticas, em experiências com drogas alucinógenas, em ideias como a de "eterno retorno", etc.

Observe-se também que, no ponto máximo de aproximação da extinção que o movimento pode atingir, inevitavelmente ocorre uma suspensão, ainda que por um átimo, do caráter opositivo que qualifica as formações que estão em jogo nas situações do mundo. Trata-se de uma indiferenciação dos sentidos das formações, a qual indiferenciação é vista justamente como o processo que possibilita transformar e as ultrapassar nossas limitações, isto é, a criação das próteses que caracterizam nosso modo de existir. Vimos, então: o conceito de pulsão; a impossibilidade de atingir seu objetivo de extinção absoluta; o processo de indiferenciação e consequente criação; e a idéia de que as formações que existem são resistências ao movimento pulsional. Note-se que pensar que tudo que há são formações ${ }^{18}$ implica também considerar o recalque que sustenta a existência de qualquer formação. Recalque este que jamais é definitivo, mas que, momentaneamente ${ }^{19}$, busca excluir a manifestação de formações opostas às que estão em vigor e, junto, paralisar o processo de indiferenciação e transformação. Portanto, toda formação sempre se apresenta como um recalque no campo das possibilidades de manifestação. Por isso, as rebeliões (sociais, científicas ou outras) que acompanhamos no decorrer da história, podem instaurar novas formações, mas não têm como evitar que, uma vez hegemônicas, estas se tornem recalcantes de outras tidas como ameaça à sua configuração.

\section{Vínculos relativos e vínculo absoluto}

Retomemos a expressão quod me nutrit, me destruit (o que me alimenta me destrói), adotado pelas anas. Se invertermos seus termos, verificaremos que o que busca afirmar não desfaz o sentido de impossibilidade comum a todos, anoréxicos ou não, que é aquele direcionado à própria extinção. Se pensarmos "o que me desnutre, me constrói" - lema que continua compatível com a causa das anas -, torna-se clara sua impossibilidade, pois, desnutrindo totalmente o corpo, só se construiria o simultâneo definhar da instância que deseja desnutrir-se. Isto significa a realização do objetivo de extinção? Não, pois se mantém o sentido fundamental ao movimento presente em qualquer formação, já que, como dito no item anterior, é impossível realizar-se a extinção absoluta estando presente a esta extinção. Vemos, então que, no caso, o alegado objetivo de perfeição corporal só seria obtenível em sua não-consecução postergada. 
Mas podemos visualizar aí uma boa expressão tanto da inevitável condenação a existir sem saída da existência, quanto do fato de que é dentro desta condenação que se produzem e se transformam nossos vínculos. Se considerarmos que tudo que se manifesta força à vinculação e que somos seres essencialmente vinculares, como supõe outro conceito freudiano importante, o de transferência (Übertragung), será possível estabelecer uma gradação geral para os vínculos ${ }^{20}$. Consideraremos relativos os vínculos presentes nas rotinas do mundo (amor/ ódio, por exemplo) por serem demasiado dependentes de nossas formações biológicas e culturais, as quais, por mais sofisticadas que sejam, são reativas a qualquer tentativa de modificação de sua configuração.

Concebe-se, entretanto, um tipo de vínculo que não é relativo, o vínculo absoluto, no qual ocorre a suspensão das oposições, ou seja, a possibilidade de indiferenciação, mencionada acima, que os humanos portam como distinção para com os demais vivos (Magno, 1993, p. 9). Todos, então, se vinculam absolutamente a essa possibilidade de indiferenciação, e não entre si. Neste vínculo, a referência é diretamente ao sentido do movimento pulsional e qualquer conteúdo se relativiza necessariamente, pois a única diferença que importa é aquela intransponível entre a existência de tudo e a não-existência de saída, embora esta seja sempre requisitada. É a enorme massa dos recalques que caracteriza o cotidiano dos vínculos relativos que impede nossa referência indiferenciante de ser operativa com mais freqüência, e, portanto, impede que a força de (re)pressão desses vínculos sobre nossa existência seja relativizada pelo vigor do vínculo absoluto.

No trecho de música mencionada no item 3 - "Será que ninguém aqui vai te deixar desaparecer?" -, podemos, então, constatar uma boa percepção do fato de que a vincularidade ao movimento para a extinção e à impossibilidade de realizá-lo jamais desaparecerá e pressionará sempre por menor que seja o peso corporal atingido, pois a nada que exista é dada a possibilidade de não ter "aparecido", ou seja, de não ter existido vincularmente. Esta constatação nos possibilita detectar nos sites ana e mia, além da expressão de algo problemático para os envolvidos, um modo de expor que somos todos absolutamente vinculados ao próprio fato de sermos "vinculares" (Magno, 1993, p. 42). Isto, para além das aparências e conteúdos que os vínculos tomam em suas manifestações no mundo.

\section{Transformação dos vínculos no ciberespaço}

Podemos agora ensaiar algumas respostas às perguntas do final do item 2. Efetivamente, a conexão em redes sociais na internet tem propiciado a expressão de vontades vinculares existentes desde sempre, mas sem antes dispor dos canais adequados à especificidade de suas demandas. O "anonimato" é uma das características facilitadoras desta expressão - mas só é anonimato em relação aos papéis sociais ou selfs restritos que a cultura define de saída como desejáveis a cada um. Não é possível supor que anas e mias ignorem que seus websites, além dos adeptos, também serão visitados por aqueles a quem apontam como responsáveis pelas não-realizações de suas metas. Dar dicas públicas de como disfarçar o ruído dos vômitos no banheiro, por exemplo, não deixa de ser um modo de anunciar a pais e outros o que lhes está acontecendo.

Um efeito importante desta veiculação é, pois, transformar o modo de tratar o acontecimento, tanto da parte dos que o vivem quanto dos que convivem com ele, e mesmo dos que pensam sobre ele. Uma vez em rede, e justo por isto, o próprio acontecimento passa a não mais se qualificar apenas pelas características anteriores à sua veiculação: todos, queiram ou não, passam a estar concernidos e novos passos se disponibilizam para a consideração dos fatos. Isto não significa que sejam necessariamente passos mais adequados, e sim que a questão se reconfigura - e, portanto, também se torna disponível à proposição de ações mais compreensivas (no sentido de includentes) em relação ao que está em jogo na situação.

Outro aspecto a ser considerado é que a interconectividade, para além do "interagir com outros usuários", a todo momento propõe ultrapassamentos da configuração atual do que se veicula. Isto não implica obrigatoriamente a tentativa de constituição de algum self (noção esta, aliás, demasiado presa à idéia de sujeito criticada no item 2). Ao contrário, as possibilidades de construir e assumir avatares e nicknames em diversos ambientes de socialização mediados por computador propiciam mais a disponibilização para a experiência de todos os selfs ${ }^{21}$, quaisquer que sejam, e permitem condensações e deslocamentos de personagens, cronologias e acontecimentos tidos por impossíveis ou perigosos fora do ciberespaço - o qual, por sua estrutura em multiconexão, não tem como impedir a vigência do que Freud chamou de "psicose controlada" em relação ao que ocorre nos sonhos ${ }^{22}$. Aliás, esta vigência na estrutura do ciberespaço é que leva autores como Steven Johnson (2005) a afirmar que, na prática de videogames, ocorre uma ampliação da inteligência.

Admitindo-se, então, que sites ana e mia se constituem como "redes sociais" (Recuero, 2005), nem por isso é preciso entendê-los como "comunidades" (virtuais ou outras), mesmo que este termo seja usual na web. A indicação ao longo deste artigo é, ao contrário, a de um tipo de socialidade capaz de incluir a referência à vinculação absoluta, a qual escapa a abordagens de tipo sociológico que operam com a noção de comunidade. Mediante esta referência é possível acompanhar o movimento de forçar, por mais estranho que pareça (negar-se a comer, por exemplo), sobre dada vinculação restrita demais para incluir a pressão de elementos que, embora anteriormente excluídos, não cessam de reivindicar seu direito à expressão ${ }^{23}$. O sentido deste forçar, é de indiferenciar o caráter relativo dos vínculos, suscitando ao 
máximo a expressão de todos os conteúdos envolvidos (manifestos ou recalcados) para que, de novo, se configurem nos jogos das formações. Uma vez que este empuxo diferença / indiferença / nova diferença é visto como incessante e indestrutível, justifica-se pensar uma possibilidade vincular apta a acolhê-lo como operativo em todas as suas instâncias.

Ao se expressarem em ambientes multiacessáveis, anas, mias ou outros envolvidos não podem mais conter os reviramentos inerentes e inevitáveis ao desenrolar de qualquer manifestação neste ambiente. No caso em estudo, queira-se ou não, evidencia-se o caráter relativo dos vínculos propostos de início (suporte a anorexia e bulimia como "estilo de vida", por exemplo) justo por se demonstrarem relativos demais às posições daqueles contrários ao que propõem (os "comedores de açúcar" citados em Recuero, 2005, p. 7). É desta ordem de evidenciação que pode surgir a chance de in-diferenciação entre (a) anas/mias, que se colocam de um lado, e (b) comedores, de outro - e ocorrer algum apontamento para a vinculação absoluta, já que todos, quaisquer que sejam seus "estilos de vida", se movimentam no inexorável empuxo de sair de uma existência sem possibilidade de saída. As conseqüências políticas deste modo de abordagem são inúmeras, pois indiferença na acepção que empregamos não é desprezo ou descaso, e sim pleno interesse por todas as manifestações - ampliando-se, assim, infinitamente o campo das possibilidades de comunicação e intervenção. FAMEcos

\section{NOTAS}

* Apresentado no VI Encontro Regional de Comunicação, da Faculdade de Comunicação/UFJF, 07 novembro 2008, e no I Colóquio em Imagem e Sociabilidade, da Faculdade de Filosofia e Ciências Humanas / UFMG, 13 novembro 2008.

1 Quadros descritos pelos médicos desde os anos 1690.

2 Quadro este descrito desde 500 a.C.

3 Como se lê numa comunidade do Orkut: "sou uma pro ana mia tenho isso admiro nunca vou deixar de ser poq isso e um estilo d vida n uma 'doença' como os otros que nao entendem julgam. quero ter amigas anas e mias para trocamos ideias dicas por so quem e entende tudo".

4 Por exemplo:

http:/ / belezademorrer.googlepages.com/sitesqueincentivam, acessado em 15 out 2008 .

5 Cf.: http://tudosobreanaemia.blogspot.com/2008/05/ carta-da-anacompleta.html, acessado em 15 out 2008 .

6 Cf.: http://ana_mia_forever.nireblog.com/post/ 2008/01/21/carta-da-mia, acessado em 15out 2008.
7 “Ambas as pulsões seriam conservadoras (...) visto que estariam se esforçando para restabelecer um estado de coisas que foi perturbado pelo surgimento da vida. O surgimento da vida seria, então, a causa da continuação da vida e também, ao mesmo tempo, do esforço no sentido da morte. E a própria vida seria uma conciliação entre essas duas tendências" (Freud, 1923,p. 56).

8 Experiência de existir e de ser impossível negar esta existência.

9 Linhagem cuja descrição pode ser acompanhada, por exemplo, em (Badiou, 1989,p. 12).

10 Modos que definem os focos dos sites de redes sociais (Recuero, 2008, p.38).

11 Expressões utilizadas por Motardo e Passerino (2006) referentes aos blogs como espaços de socialização mediados por computador.

12 Mantemos o termo "humano" com a ressalva de que se tornou problemático diante das atuais questões ligadas ao "pós-humano", ao "pós-orgânico", aos "ciborgues", entre outras (Kurzweil, 2005), que, para além do humanismo, ou do 'antropos', incluem o que diz respeito a seres resultantes da fusão das inteligências biológica e não biológica, i.e., da combinação das sutilezas da inteligência humana com a velocidade e a habilidade das máquinas em compar-tilhar conhecimento.

13 Observação realizada em 30 jun 2008.

14 http://new.music.yahoo.com/blogs/jill_sobule/ 716/pro-anorexia-songs-lucy-at-the-gym-and-supermodel

15 http://www.songmeanings.net

16 Diz Samuel Beckett (1957): “Você está na Terra; não há cura para isso" (apud Phillips, 2008). Diz também Philip Roth nas últimas linhas de Homem Comum (Everyman): "Ele perdeu a consciência, sentindo-se longe de estar derrubado, de estar condenado, ansioso para realizar-se mais uma vez, e no entanto nunca mais despertou. Parada cardíaca. Deixou de ser, libertou-se do ser sem sequer se dar conta disso [He was no more, freed from being, entering into nowhere without even knowing it]. Tal como ele temia desde o início" (2006, p. 131).

17 Santa Teresa: "Do desgosto que lhe inspiram as coisas do mundo, nasce na alma um desejo de sair dele. Seu único alívio é o pensamento de que Deus a quer viva neste desterro" (1577, p. 112). 
18 Para um aprofundamento do conceito, $c f$. (Medeiros, 2008, p. 4): "Por formação entende-se toda e qualquer forma, ordenação, articulação ou estrutura que há, das partículas e anti-partículas a uma ordenação simbólica (humana) qualquer, do código genético e dos ecossistemas vivos a todo tipo de técnica, língua, conhecimento ou arte. Ou ainda, toda e qualquer forma comparecente como matéria, vida ou artefato, para usar os termos das teorias da complexidade e da auto-organização [...]"

19 O que pode significar milênios, dado o investimento necessário à sua suspensão. Por exemplo, suspensão do imperativo recalcante da lei da gravidade com a teoria da relatividade, ou dos dois mil anos de dominância do cristianismo no Ocidente com a difusão da tecnologia e seus efeitos sobre o entendimento dos processos biológicos e mentais[...]

20 A teoria dos vínculos já foi exposta em "Vínculo absoluto \& vínculos relativos: comunicação e psicanálise" (Silveira Jr., 2006, pp. 49-64).

21 É inevitável aqui a referência à heteronímia de Fernando Pessoa, sobretudo por tomar o próprio "Fernando Pessoa" como heterônimo (Silveira Jr., 2006, pp.102, 119-132).

22 Isto se deve ao fato de o acesso à motilidade não estar disponível no sonho. Por analogia, a seguinte citação pode ser um bom indicativo quanto ao que ocorre na rede: "Na vida de vigília, o material suprimido da mente é impedido de encontrar expressão e isolado da percepção interna devido ao fato de as contradições nele presentes serem eliminadas - um dos lados sendo abandonado em favor do outro -, mas, durante a noite, sob a influência de um impulso à formação de compromissos" - isto é, à formação de vínculos ,"esse material suprimido encontra meios de forçar seu caminho até a consciência" (Freud,1900, p. 646).

23 Movimento este denominado "retorno do recalcado" por Freud.

\section{REFERÊNCIAS}

BADIOU, Alain. Manifeste pour la philosophie. Paris: Seuil, 1989.

BUSSE, Salvador de Rosis (org.). Anorexia, bulimia e obesidade. São Paulo: Manole, 2004.

BECKETT, Samuel. [1957] Fim de partida. São Paulo: Cosac Naify, 2002.

FREUD, Sigmund. [1923] O Ego e o Id. ESB, vol. XIX. Rio de Janeiro: Imago, 1976. p. 11-83
. [1920] Além do princípio de prazer. ESB, vol. XVIII. Rio de Janeiro: Imago, 1976. p. 13-85

. [1900] A Interpretação dos sonhos. ESB, vols. IV e V. Rio de Janeiro: Imago, 1972.

JOHNSON, Steven. Everything bad is good for you. How today's pop culture is actually making us smart. Nova York: Riverhead books, 2005.

KURZWEIL, Raymond. The singularity is near: When human transcend biology. Nova York: Viking, 2005.

MAGNO, MD. [1993] A Natureza do vínculo. Rio de Janeiro: Imago, 1994.

. [1986] Pleroma. In: [1986-87] O Sexo dos anjos: a sexualidade humana em psicanálise. Rio de Janeiro: A outra editora, 1988.

MEDEIROS, Nelma. O primado heurístico da noção de "formação": para uma teoria gnóstica do conhecimento. Lumina: Revista do PPGCOM/UFJF. Vol.2, n. 2, 2008. Disponível em: http:/ / www.ppgcomufjf.bemvindo.net/lumina/index.php?journal= edicao\&page =article\&op =view\&path []$=69 \&$ path []$=84$

MONTARDO, Sandra Portella; PASSERINO, Liliana Maria. Estudo dos blogs a partir da netnografia: possibilidades e limitações. Novas Tecnologia na Educação. Revista Novas Tecnologias de Informação, Porto Alegre, v. 4, n. 2., 2006. http:// www.cinted.ufrgs.br/ renote/dez2006/artigosrenote/25065.pdf

PHILLIPS, Adam. De perto, ninguém é normal. In: Folha de São Paulo, Mais, 20 julho 2008, p. 4.

RECUERO, Raquel. Estratégias de personalização e sites de redes sociais: um estudo de caso de apropriação do Fotolog.com. In: Comunicação, mídia e consumo. ESPM. São Paulo, vol.5, n. 12, p. 35-56, mar. 2008.

. Comunidades em redes sociais na internet: um estudo de uma rede pró-ana e pró-mia. Faro, Valparaíso, v. 1, n. 2, 2005.

ROTH, Philip. [2006] Homem comum. São Paulo: Companhia das Letras, 2007. Trad.: Paulo Henriques Britto.

SANTA TERESA DE JESUS. [1577] Castelo interior ou moradas. 10ed. São Paulo: Paulus, 2002.

SILVEIRA Jr., Potiguara Mendes da. Artificialismo total. Ensaios de transformática. Comunicação e psicanálise. Rio de Janeiro: NovaMente, 2006. 